\title{
JUNGLE CAT (FELIS CHAUS SCHREBER, 1777) POPULATION DENSITY ESTIMATES, ACTIVITY PATTERN AND SPATIOTEMPORAL INTERACTIONS WITH HUMANS AND OTHER WILDLIFE SPECIES IN TURKEY
}

\author{
ÜNAL, Y. $.^{*}-$ ERYILMAZ, A. ${ }^{2}$ \\ ${ }^{1}$ Isparta University of Applied Sciences, Faculty of Forestry, 32260 Isparta, Turkey \\ ${ }^{2}$ Isparta University of Applied Sciences, The Institute of Graduate Education, 32260 Isparta, \\ Turkey \\ *Corresponding author \\ e-mail: yasinunal@isparta.edu.tr \\ (Received $6^{\text {th }}$ Mar 2020; accepted $10^{\text {th }}$ Jul 2020)
}

\begin{abstract}
Although the jungle cat (Felis chaus) has been listed as a species of Least Concern - (LC status) by IUCN data, there are many threats endangering the population of the jungle cat in Turkey. Currently, relatively little is known about their population status and ecology. Our study aims to determine the jungle cat's population density, interactions among humans and other wild animals, and the diel activity patterns. This research was carried out in the northern part of Eğirdir Lake within the borders of Isparta province between March 2016 and July 2017. Presence absence studies were carried out and evaluated using 15 camera traps, placed in 193 stations based on the opportunist method in areas where trail-marks of the jungle cat were detected. Throughout the study 83 camera trap data belonging to jungle cats over 4403 camera trapping days were obtained from 193 stations. This study provides the 1st robust estimation of the jungle cat population size and spatiotemporal interactions of humans and other wildlife species in Turkey. As a result of this study, it was concluded that human activity affects wildlife behavior and that wild animals are haivng to adjust their living and feeding behaviors according to human activity. How human activity affects wildlife behavior. Our study underlines the need to consider activity patterns of wildlife for conservation and environmental management planning.
\end{abstract}

Keywords: human-wildlife interactions, terrestrial mammals, camera trapping, capture-recapture, diurnal-nocturnal, human pressure, Turkey

\section{Introduction}

In recent years, wildlife have been subject to increased threat by human-induced activity such as narrowed and fragmented habitats, dwindling numbers of prey in their natural areas, and inadequate nutrition due to the proximity of human settlements (Kerley et al., 2002; Treves and Karanth, 2003; Dhungana et al., 2017). Factors including industrialization, forest fires, increased tourism, as well as illegal and excessive hunting all contribute to habitat destruction (Soyumert, 2010; Ünal and Çulhac1, 2018). Despite differences in these mortality factors affecting various species in different parts of the world, researchers agree that human-induced threat is a global problem and is observed largely in carnivorous species (Durant, 1998; Bisi et al., 2007; Rawshan et al., 2012; Seoraj-Pillai and Pillay, 2016).

Despite Turkey's rich biodiversity, 8 of the 21 terrestrial predator populations have been decreasing in numbers due to the factors mentioned above (Can and Togan, 2004; Capitani et al., 2016). Among these species, the grey wolf (Canis Lupus), Eurasian lynx (Lynx lynx) (Chynoweth et al., 2015), brown bear (Ursus arctos) (Ambarlı et al., 2016) and caracal (Caracal caracal) (Giannatos et al., 2006; Ilemin and Gurkan, 2010; Oğurlu and Ünal, 
2011; Ünal et al., 2019). The jungle cat (Felis chaus) is one of the five cat species still found in Turkey, along with the Eurasian lynx, Caracal, wild cat (Felis silvestris) and Anatolian leopard (Panthera pardus) (İlemin and Gurkan, 2010; Gerngross, 2014). The jungle cat is a medium-sized, long-legged cat, and the largest of the extant Felis species. The head-andbody length is typically between 59 and $76 \mathrm{~cm}$ (Ery1lmaz, 2017). The species was first recorded in Turkey in 2007 around the Adana - Akyatan Lagoon (Avgan, 2009). Even though the jungle cat has been listed as Least Concern (LC) by 2018 IUCN data, jungles cats have struggled to survive due to increased human threat, including the conversion of swamps into agriculture areas, excessive destruction and burning of wetland reeds, eradication of rodents and extensive use of pesticides (Linnell et al., 2001; Madden, 2008; Gray et al., 2016; IUCN, 2018).

In recent years, the use of camera traps in population studies of rare terrestrial mammals has gradually increased (Silveira et al., 2003; Evcin et al., 2017). With the development of technology, reduced costs and effective results compared to other methods, cameratrapping has become the preferred method of study (Tobler et al., 2008). This method has an important role in the detection of rare terrestrial predatory mammals, including the jungle cat, and is practical for monitoring relative and absolute abundance, and obtaining data related to population condition, species behavior, habitat preferences, and diel activity patterns (Kays and Slauson, 2008; Kays et al., 2010; Linkie and Ridout, 2011). Both opportunist and systematic methods are used in wildlife studies in conjunction with camera trapping to obtain information about species populations. The Opportunist method ensures maximum data by taking into account the maximum use of space of a target species spread across a certain area (Soyumert, 2010). Data is acquired by deploying camera trap stations close to the paths, tracks and signs of the target species, their nest location, feeding places, and areas that supply water (Ünal et al., 2019).

Camera trapping studies performed on species with patterned furs, such as the jungle cat, tiger (Panthera tigris) (Karanth et al., 2006), lynx (Weingarth et al., 2012), and wild cat (Can et al., 2011), increases the importance of individual identification and population density research by means of fur patterns that are unique to individuals (Carbone et al., 2001; Mengüllüoğlu, 2010; Alfred, 2015).

The ability and degree to which terrestrial carnivores can coexist with humans over a sustained period of time is a considerable issue in conservation science and policy (Woodroffe et al., 2005; Dickman et al., 2011; Carter et al., 2012). Numerous research projects have been carried out to facilitate coexistence at different spatial scales. Over the past decade human and wildlife interactions have been shown as one of the most important problems limiting the number of species that can occupy an assemblage as a result of their similarity in habitats (Sillero-Zubiri and Laurenson, 2001; Di Bitetti et al., 2009). Terrestrial predators are the living group directly affected by these interactions, regardless of their size (Bisi et al., 2007). Although rural settlements consistently express negative attitudes toward large carnivores, they often constitute a minor problem compared with plant and forest pests such as microtine rodents and feral dogs (Ünal et al., 2020). If terrestrial predators do not harm agricultural areas or pets of local people, positive interactions can be mentioned rather than conflict (Durant, 1998; Rawshan et al., 2012). In such positive interactions, predatory mammals find ways to minimize spatiotemporal encounters with humans even though they have spread around human settlements (Ramesh et al., 2012). In this regard, Carter et al. (2012), report tigers in Nepal's Chitwan National park offsetting their temporal activities, especially outside the park, by being less active during the day when human activity peaked. Tiger population density is high despite the daytime human density in this protected area. 
Capture-Recapture models are used to analyze population density. This model has become more prominent because it allows for individual diagnosis of spotted pattern structure of jungle cats in order to estimate population size. Many studies using records about target species, reveal data obtained by the statistical proportion of the captured, recaptured and freely captured individuals (Hammond, 2009; Urian et al., 2014).

Previous research conducted on observed problems including habitat loss, severe poaching of wildlife, human-jungle cat interactions, and direct threat to the jungle cat population (Oğurlu et al., 2010). Wildlife experts need comprehensive inventory data to effectively manage and conserve jungle cats in this region. Our study aims to determine the jungle cat's population density, interactions among humans and other wild animals, and the diel activity patterns.

In this study, we test three specific hypotheses: (i) despite high human density the jungle cat has a positive spatial interaction with humans if it can survive (ii) jungle cats are more active at night to avoid human disturbance and (iii) jungle cat spatiotemporal patterns overlap those of other wild animals. To test these hypotheses empirically, we used camera trapping.

\section{Materials and methods}

\section{Study area}

This research was carried out in habitats around Eğirdir lake particularly in the southern part of the north section of the lake (38015'K-30052'D), located within the borders of Eğirdir, Gelendost, Yalvaç and Senirkent districts in the province of Isparta. Eğirdir lake is the fourth-largest lake, but also the second-largest freshwater lake in Turkey. In addition to being a suitable habitat for spawning fish due to its shallowness and reed field (Fig. 1) (Fethi et al., 2014; Tağıl and Alevyakalı, 2014), Eğirdir Lake, shows the characteristics of being an important feeding area for jungle cats (Oğurlu et al., 2010).

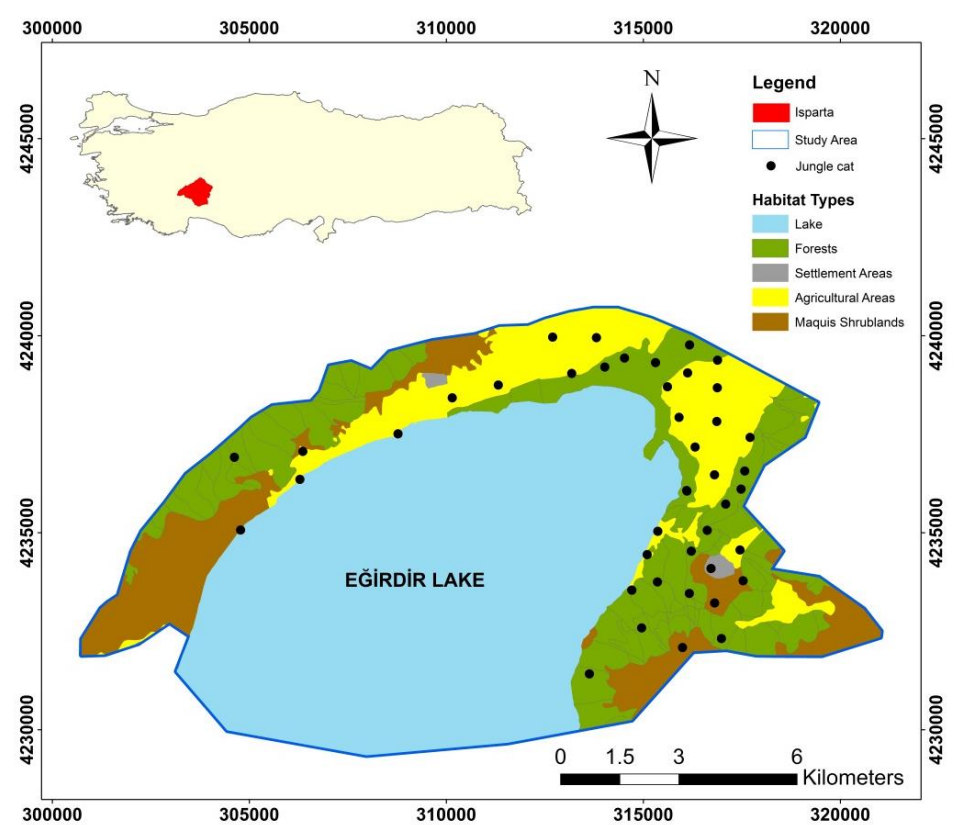

Figure 1. Location map of the study area 
The area is approximately $10.7 \mathrm{~km}^{2}$. In addition to intensive agriculture, fishing, grazing of livestock, and hunting activities are carried out in most parts of the area. There are 4 villages in the research area where the jungle cat interacts directly. $33.1 \%$ of the locals in the village are engaged in agriculture, $12.5 \%$ in livestock and $3.1 \%$ in fishing. The climate of the region is in a transition zone between Mediterranean and Central Anatolian climates. Precipitation varies $63 \mathrm{~mm}$ between the driest and wettest months of the year, while the average temperature throughout the year is approximately $20.2^{\circ} \mathrm{C}$.

In the research area, shrubs, such as kermes oak (Quercus coccifera), colutea (Colutea melanocalyx), terebinths (Pistacia terebinthus) and ephedra (Ephedra major), yellow jasmine (Jasminum fruticans), narrow-leafed ash (Fraxinus angustifolia) and manna ash (Fraxinus ornus) are found in low altitude habitats near the lake. Foetid juniper (Juniperus foetidissima) and European barberry (Berberis crataegina) were spread in relatively rugged habitats up to 1400 - 1500 meters. Above 1500 m, Junipers were scattered throughout an alpine zone (Karatepe, 2004).

\section{Data collection}

During the research period, 15 camera traps were deployed in 193 camera trap stations using the opportunist method (Harmsen et al., 2011). Google Earth, ArcMap 10.4 and Microsoft Excel programs were used to display the camera trap stations on the map. KeepGuard Color Viewer (KG860) camera traps were used, featuring non-glare infrared shooting, 12 MP maximum resolution ability, 0.25 seconds trigger time, 25-meters night vision distance, simultaneous 1-5 photo capture, and video capture (Mengüllüoğlu et al., 2019).

Camera traps were positioned in suitable and sheltered tree trunks ranging within 0.30-1.00 $\mathrm{m}$ from the ground (Amaya-Castaño and Palomares, 2018). Each camera trap period was designated as an average of 30 days. The total number of days that all camera traps were actively working since the date of their establishment, namely the "camera trapping day value", was calculated as 4403; (Table 1) (Stein et al., 2008).

Table 1. Number of camera trappings, ratio, and days captured

\begin{tabular}{c|c|c|c|c|c}
\hline Species & $\begin{array}{c}\text { Camera trap } \\
\text { day }\end{array}$ & Num. of photos & Prop. of photos & Days captured & $\begin{array}{c}\text { Num. of } 100 \\
\text { Days Captured }\end{array}$ \\
\hline Felis chaus & & $\mathbf{8 3}$ & $\mathbf{3 . 1}$ & $\mathbf{7 7}$ & $\mathbf{1 . 8 9}$ \\
Human & & 135 & 5.2 & 88 & 3.07 \\
Canis aureus & & 1115 & 24.07 & 283 & 13.95 \\
Sus scrofa & & 43.5 & 358 & 25.32 \\
Lepus europaea & 4.403 & 224 & 5.1 & 95 & 3.09 \\
Vulpes vulpes & & 37 & 1.5 & 156 & 5.09 \\
Martes foina & & 3 & 0.8 & 37 & 0.84 \\
Canis lupus & & 205 & 8.03 & 3 & 0.07 \\
Livestock & & & 123 & 4.66 \\
\hline
\end{tabular}

\section{Data analysis}

The jungle cat is a long-legged and relatively short-tailed wild cat. Although individuals differ in color and patterns, they are generally gray. Individuals can be identified by unique asymmetrical patterns and lines covering both sides of the legs and body. The most distinct of these natural marks are the patterns on the hind legs. Small differences in these marks enable individuals to be distinguished from each other 
(Fitzgerald, 2011). Individuals were recognized based on the identification of strips on their hind legs from the jungle cat camera trap records using the WildID camera trap record assessment program (Carter et al., 2013). The striped patterns on the hind legs were drawn on individuals using Microsoft Powerpoint. Images were compared and individual jungle cats were assigned a unique identifier number (Mengüllüloğlu, 2010; Avgan et al., 2014; Ünal and Culhac1, 2018) (Fig. 2).
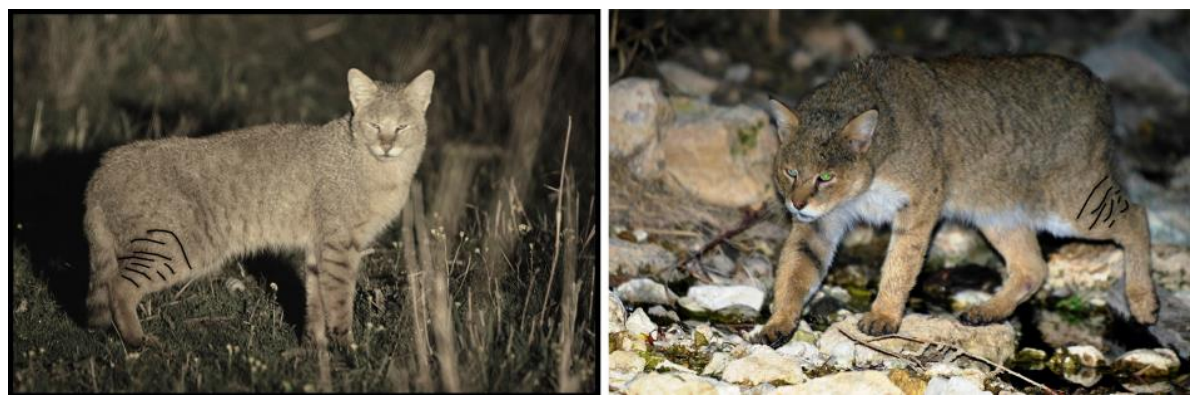

Figure 2. Two jungle cat individuals with unique fur patterns on their hind legs in the study area. Patterns were identified to based on both of camera trap and photo records using the WildID camera trap record assement program. Patterns were highlighted for visualization using Microsoft Powerpoint (Photo: Ogün Çağlayan TÜRKAY)

Camera trap recordings were used to determine the daily activity patterns of jungle cats, other wild animals and humans. On certain occasions, individuals were captured more than once at single a camera station over a 5 minute period. Thus, to avoid pseudoreplication, we considered the 1st capture of the animal as an independent record, and subsequent captures within the 5-min time frame were censored. We tested the mean activity pattern of jungle cats, other wild animals and humans using ORIANA 4.0 Software. This software offers a wide range of analyses including rose diagrams, circular histograms, raw data plots, arrow data plots and linear histograms. The rose diagram is a histogram displayed in a circle, similar to the pie chart for linear data. However, each sector represents the frequency or number of observations that falls in the range of angles. The concentric circles show the frequency of the observations for each angular value (Hassan et al., 2009). To detect daily activity patterns of target species, the 24-hour period is divided into hourly sections, and each independent record is classified within these intervals (Pérez-Irineo and Santos-Moreno, 2016). The diel activity pattern graph was formed by evaluating camera trapping data appropriately. A rose diagram was prepared using ORIANA 4.0 (Kovach, 2011; Ünal, et al., 2019).

In order to determine the effect of human activity and presence on jungle cat and wildlife populations the risk ratio (RR) as a measure of effect size was calculated for each species. The percentage of activity that occurred at night (by camera trap) at sites or during seasons of high human disturbance $(\mathrm{Xh})$ was compared with nighttime activity under low disturbance $(\mathrm{Xl})$, using the equation 1.

$$
R R=\ln (X h / X l)
$$

A positive RR indicated a relatively greater degree of nocturnality than diurnality in response to humans, while a negative RR indicated reduced nocturnal behavior. Sampling variance $(S)$ of effect size was calculated using GraphPad Prism 8 random-effects models. 
These models estimated the overall effect of human disturbance on jungle cat and other wild animals (Gaynor et al., 2010).

We used the Capture-Recapture model in order to estimate the jungle cat population (Grimm et al., 2014). This model, allows for the comparison and combination of statistical methods and identifies the minimum, maximum and average results of the population (Soria-Díaz and Monroy-Vilchis, 2015). Therefore, in the CAPTURE2 software, using Jackknife-M (h) (Silver et al., 2004), Chao M (h) (Karanth, 1995) Zippen-M (b) and Removal-M (bh) (Forbes et al., 2014) approach, we obtained the minimum and maximum population density. To evaluate the accuracy of the results, we used 3 different methods;

Lincoln-Peterson Index

$$
\text { T: }((\mathrm{X}+1)(\mathrm{x}+1)) / \mathrm{y}+1)-1
$$

Bailey's Modification Index

$$
\dot{\mathrm{T}}:(\mathrm{X}(\mathrm{x}+1)) /(\mathrm{y}+1)
$$

Schnabel Method

$$
\text { T: } \sum \mathrm{t}(\mathrm{xy}) /\left(\sum \mathrm{tX}\right.
$$

Confidence intervals

$$
(\mathrm{CI} 95 \%=\dot{\mathrm{T}} \pm 1,96(\mathrm{SE})
$$

The Standard error (SE)

$$
\sqrt{\mathrm{T}} 2(\mathrm{y}-\mathrm{x}) /(\mathrm{y}+1)(\mathrm{x}+2)
$$

The initial method of Capture-Recapture studies uses the Lincoln-Peterson Index which is considered as the standard technique (Jibasen, 2011; Bukhari et al., 2019).

In this formula, $X$ denotes the number of individuals captured and marked in the first sampling, $\mathrm{y}$ is the number of individuals independently captured in the second sampling, $\mathrm{x}$ is the number of previously marked and recaptured individuals, and $\dot{\mathrm{T}}$ denotes the estimated population size (Alcoy, 2013; Pochardt et al., 2019).

\section{Results}

\section{Camera recording and density estimates}

We obtained 36491 images from 193 stations that were placed using the opportunist method by means of trace and fecal surveys carried out in the field. 3104 wild animal records $(8.50 \%)$ were derived. Over the course of the study, the camera trapping day value reached 4403. 83 jungle cat records (camera trap recording rate (RI) $3.1 \%$ ) were obtained over 77 camera trapping days. Jungle cats were found to be spread in habitats near the lake at the rate of RI: 47.5\% (Duckworth et al., 2005; Gupta et al., 2009). A total of 2550 camera trappings were obtained from other mammalian species. Apart from the jungle cat, 8 other mammal species in the region, including the golden jackal (Canis aureus), 
gray wolf, red fox (Vulpes vulpes), European rabbit (Lepus europaeus), beech marten (Martes foina), wild boar (Sus scrofa) and least weasel (Mustela nivalis) were recorded from the camera trap surveys.

Active day values of each camera trapping were assessed and recorded (Stein et al., 2008; Wang and Macdonald, 2009). Due to the difference of monthly inspection times, lost or stolen camera traps, and unequal monthly recording times, the data were converted to fix as 100 days. For this purpose the number of records/camera trapping day number equation was used (Kinnaird and O'Brien, 2012; Keten, 2016). Due to insufficient recordings of gray wolves and least weasels, these two species were not included in the analysis.

After evaluating the results from the Lincoln-Peterson index, Bailey's Modification Index and Schnabel Index, the population size was calculated in the range of $21.82\langle\mathrm{~N}\rangle$ $22.50 \mathrm{~km}^{2}$, (SI: $3.12-3.21$ ). In the CAPTURE2 Population estimation program, Removal $\mathrm{M}$ (bh) was calculated as $2.34 / \mathrm{km}^{2}$, (SI:3.16) and gave the closest population density value to index. The smallest population value of all results was calculated as Zippen-M (b): $1.96 / \mathrm{km}^{2}$ (SI:1.89) (Fig. 3).

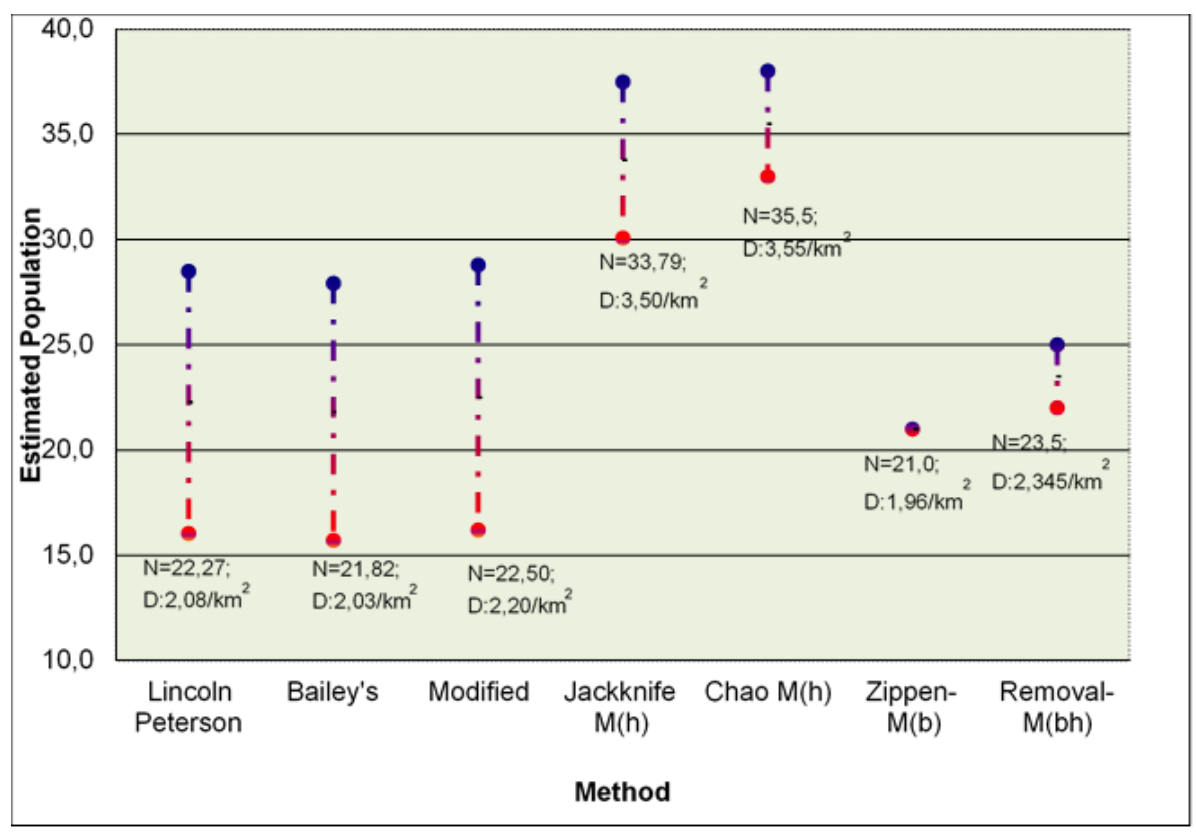

Figure 3. Comparison of population size estimate methods

\section{Jungle cat, human, livestock and other wild animals species interactions}

We measured the spatiotemporal activity patterns of six mammals and human activity in the research area (Shamoon et al., 2018). The daily changes of activity and graphic representation of rose diagrams were generated using Oriana 4.0 (Fig. 4) (Leuchtenberger et al., 2018). Our results indicated that humans were active during the day and withdrew from the field under dark conditions. Jungle cats and other wildlife on the other hand showed higher activity following human withdraw from the field. According to the GraphPad Prism 8 random-effects models no human activity was encountered between dusk and morning (RR: $-1.41 ; \mathrm{S}: 0.0405)$. Although the jungle cat is mostly nocturnal it was observed displaying diurnal behavior (RR: -0.011; S:0.0027). However, its diurnal 
behavior occurred at a lower level compared to nocturnality. Other wild animals had positive values in the range of RR: 2.97-4.373; S: 0.0412-0.989 (Fig. 5). Gaynor et al. (2010) reported that nocturnality of wild animals increased positively in habitats with intense human pressure, supporting our results. Wild boar (S. scrofa), European rabbit (L. europeaus), and beech marten ( $M$. foina) species, which typically show diurnal behavior in natural areas with low human pressure displayed limited daytime activity in our study and were only active at nighttime, once people had retreated from their fields (Posillico et al., 1995; Stolle et al., 2015).
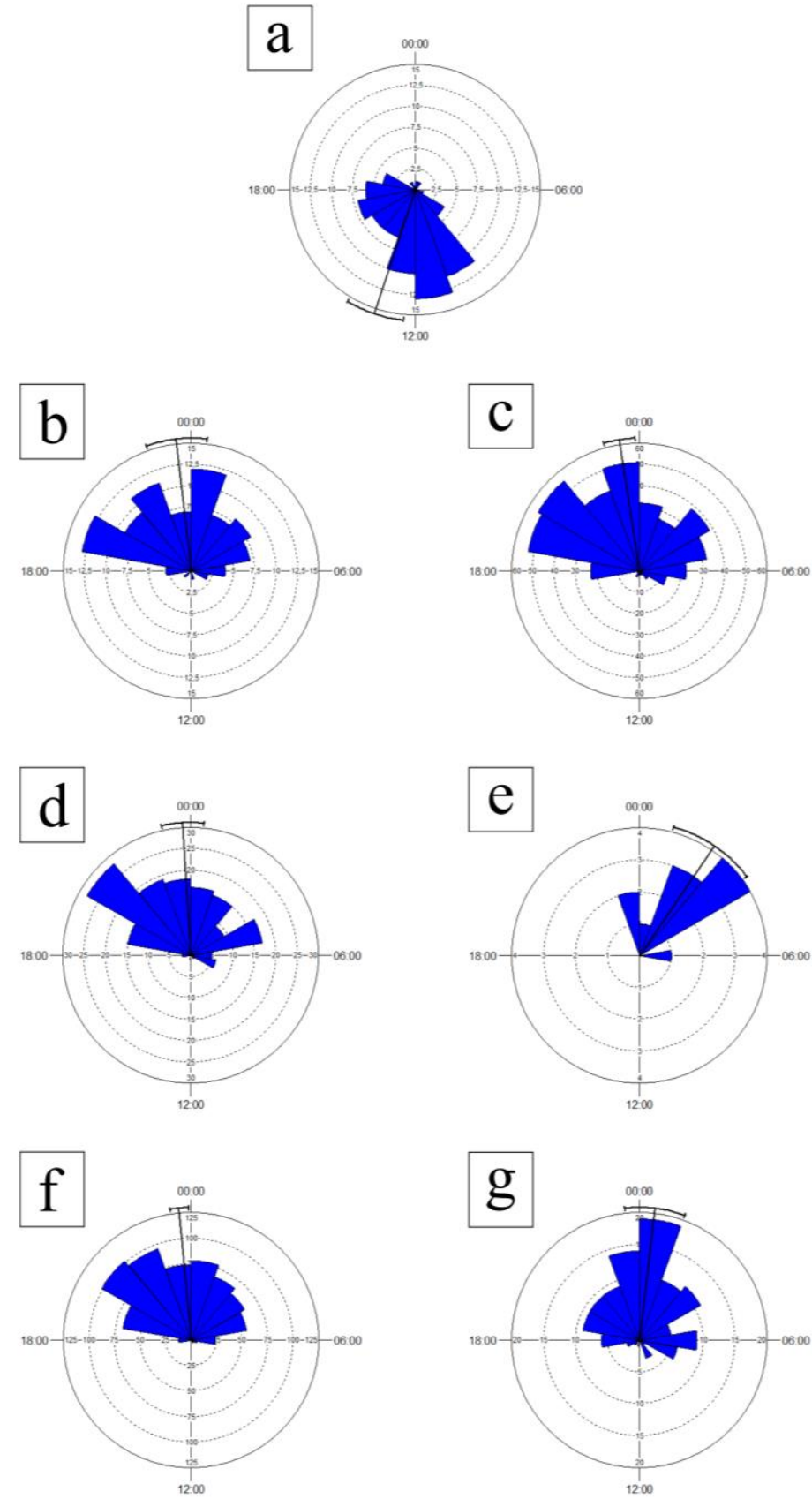

Figure 4. Temporal activity patterns a) human, b) jungle cat, c) golden jackal, d) red fox, e) beech marten, f) wild boar, g) Eupoean hare on different habitats near the Egirdir Lake in the Isparta, TURKEY: blue bars indicates mean dial activity with 95\% confidence interval 


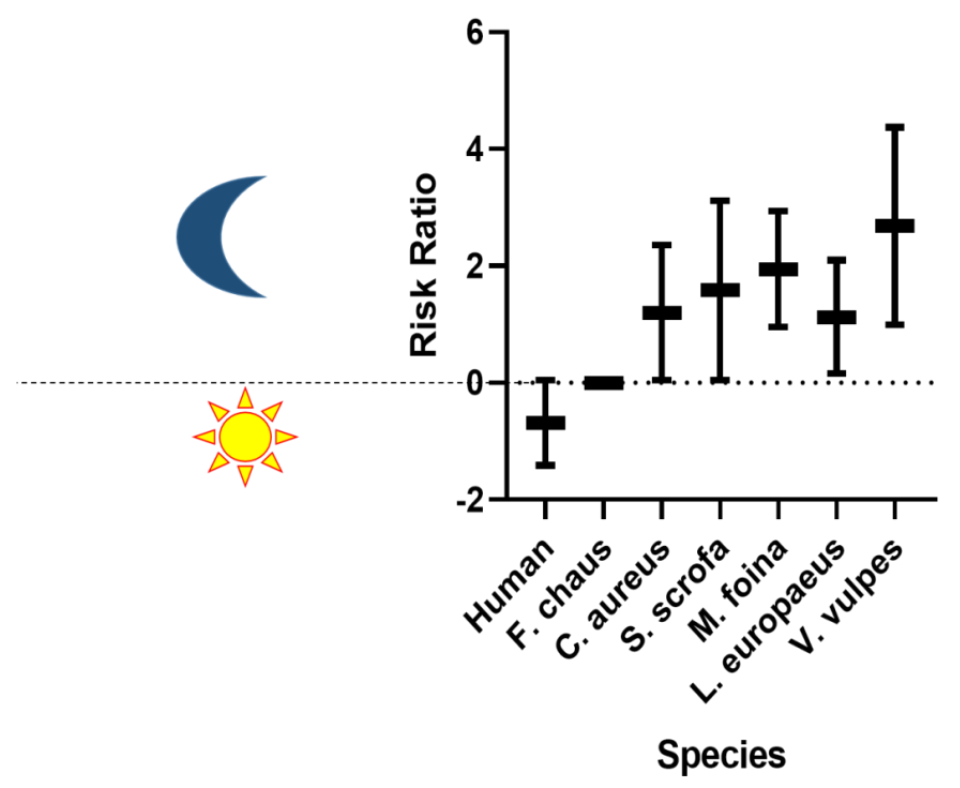

Figure 5. GraphPad Prism 8, jungle cat, human and other wild animals random-effects models

\section{Discussion}

This study was carried out in jungle cat habitat around Eğirdir Lake between 2016 and 2017. Few studies have been conducted so far about the population ecology of the jungle cat in Turkey (Oğurlu et al., 2010; Mert and Acarer, 2018). Our study was the first comprehensive study using emerging technologies such as camera trapping to reveal population density, diel activity pattern, habitat preference of the jungle cat, and its interactions with humans and other species. This study revealed nine terrestrial mammals species, occurring in the study area along with humans and livestock. The jungle cat was the only important and rare predator species in the study area. Our study results demonstrate how jungle cats respond to human presence at fine scales, as small as $10.7 \mathrm{~km}^{2}$. In our research area, we found that jungle cats adjust the spatiotemporal patterns of human activity and have a positive interaction with humans despite high human density. Furthermore, as the jungle cat is often seen in areas where human presence is ubiquitous, studies that evaluate the interconnections between jungle cats and people across different land management regimes need to be developed for robust landscape-scale conservation strategies.

Research suggests that the jungle cat's global population is declining and gradually moving towards the threatened border. The European population has been reported as rapidly declining since the 1960s. Reports from Russia identify about 500 animals remaining in the wild, while a very small population exists in Georgia (Duckworth et al., 2005). Due to the jungle cats habitat proximity to rural settlements, it has been observed that jungle cats are struggling to survive from threats such as habitat fragmentation, environmental pollution, waterbird hunting, intensive pressure from vehicles, agriculture, fishing and grazing, conversion of swamps into agricultural areas, excessive destruction and burning of wetland reeds, control of rodent populations, and heavy use of pesticides (Linnell et al., 2001; Madden, 2008; Oğurlu et al., 2010). Similarly, our study confirmed some of the stated issues contributing to the declining population of jungle cats in the 
research area. Therefore, the methodology and results of our study are vital for preserving the jungle cat populations in Turkey.

The capture-recapture model has been used for estimating densities of one of Turkey's most important predator felis species, the jungle cat. The previous conventional analyses of obtaining population density have given way to more robust methods that use the spatial information of the location of traps rather than methods that estimate the size of the effective area heuristically. It was concluded that the Capture-Recapture method gave statistically reliable results for the jungle cat population. To increase the reliability rate of results, it was ensured that the camera traps function for at least 20 days in each camera trap period, as recommended by Gupta et al. (2009) and Jansen et al. (2014). Throughout the study it was found that 15 out of 83 individuals, who were caught on camera traps over 77 trap days, were different individuals. In a camera trap period, the highest capture rate for the same camera trap was functioning as 7 records at site no_0077, near the lake. Additionally, 5 records from each of the 3 camera trap sites (fi_31, fi_106, fi_129) placed around the lake were the biggest indication that the species behaved diurnally in this habitat type (Gupta et al., 2009; Avgan et al., 2014). It is understood that the jungle cat was passive in forest habitats during the day, while it was active in habitats at point zero of the lake from the first hours of night. The jungle cat, human and livestock activity in this area appeared to be the same within the context of spatiotemporal response. Our findings suggested that jungle cats are adjusting their spatiotemporal activity patterns to people, supporting the 1st and 2nd hypotheses. The jungle cat had a positive interaction with humans despite high human density. However, there was a clear difference in temporal activity. Jungle cats were more active at night to avoid human disturbance. It is a known fact that this area is used by humans in the daytime, and by jungle cats after sunset. It is believed that the biggest reason for the jungle cat to arrive at these hours was to feed on fish scraps cleaned by fishermen or dead and live fish in the shallow part of the lake (Oğurlu et al., 2010; Oğurlu, 2015). Apart from night feeding, the jungle cat preferred to rest and isolate itself in its natural forest habitat, far from humans. The decrease in the rate of being caught on camera traps as it moved towards the forest habitats was an indicator of this case (Majumder et al., 2011).

It is clear that urban wildlife has both positive and negative interactions with humans. Historically, there has been a significant amount of research emphasis on clashes between city dwellers and wildlife. Now there is increasing recognition of the benefits that wildlife can bring (Soulsbury and White, 2015). According to our study results there was no fear of conflict between humans and jungle cats. On the contrary, cats helped farmers by eating mice on farmland and cleaned the lake environment by eating fish waste discarded by fishermen on the lakeshore. This systematic behavior of the forest cat created sympathy for the species by the locals. As a result, despite our widespread belief that terrestrial predators always clash with humans, our work has shown mutual cooperation between cats and local people (Inskip and Zimmermann, 2009; Chowdhury et al., 2015). Despite this conclusion, in order to avoid the need for human-induced harm to carnivore species in different areas, the priority of research should be focused on more humanwildlife conflict in urban areas and the human-wildlife relationship of wildlife management plans to which these species and people will be least affected. These plans need to be prepared and handled in a holistic way. There is a critical need to develop conceptual frameworks to understand human-wildlife interactions.

Jungle cats in our study site exhibited relatively high temporal overlap with other wild animals, lending some support for hypothesis 3. It was likely that jungle cats were 
deliberately active when these species were active (Fig. 6). The complex landscapes consisting of agricultural area, forest and wetlands were the most preferred habitats for wild animals. The positive interaction of the jungle cat and other wild animals using these habitats existed due to a sufficient amount of nutrients for predatory species in these areas (Wegge et al., 2009). For example, prey species, such as vole and European rabbit (Prop. of photos: $5.1 \%$ ), were relatively abundant for golden jackal, another large predator species (Prop. of photos: 24.07\%). Therefore, there was a little conflict for food sources between predators.
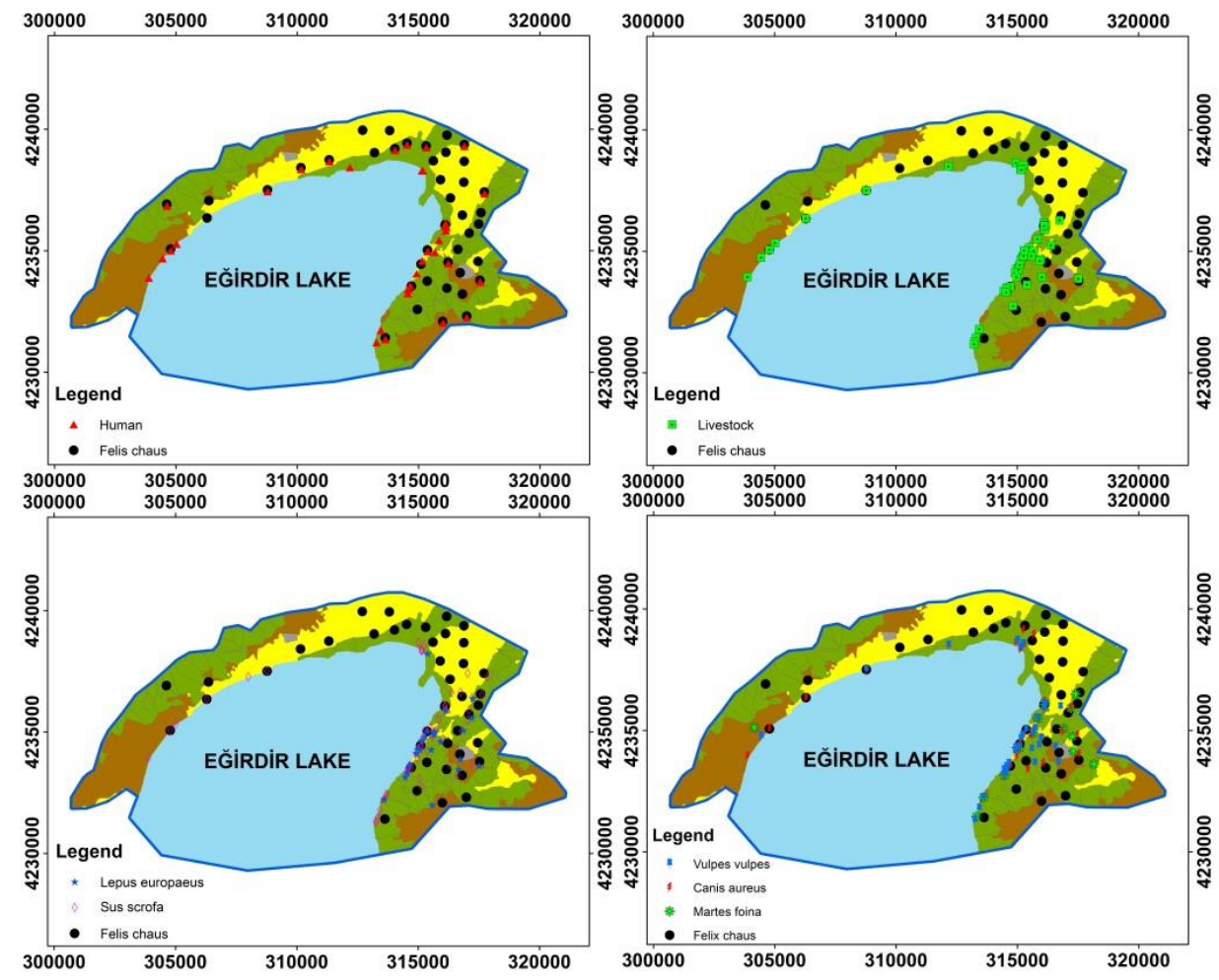

Figure 6. Location of camera traps around Eğirdir Lake in Isparta province, capturing jungle cat, human, livestock and other important species at sampling locations within the Eğirdir Lake study area located in Turkey

In our study, it was observed that all other wild animals, apart from the jungle cat, did not show any activity during the day (Fig. 6). Although humans, jungle cats and other wild animals in the area were not spatially separated, the temporal separation between them limited human contact rates (Fig. 7). With the exception of the jungle cat it is thought that nocturnal behavior in wild animals is preferred when humans have minimal activity, in order to comfortably feed and protect itself and its family. For this reason, jungle cats seen over the course of the study, smuggled or crushed on the highway supports this theory (Gaynor et al., 2010). Therefore changes in temporal niche should be taken into account by the Nature Conservation and National Parks Directorate. It is important that protection control is carried out after dark, throughout the night.

Based on the camera trap images, we observed no signs of jungle cat poaching by locals in the study, nor did we come across any snares while in the field (Carter et al., 2015). With the exception of human-boar conflict we did not encounter any conflicts between locals and wildlife (Carter et al., 2012). However, it is thought that poaching of 
jungle cats is connected to fish, frog, bird and land hunters from outside the area. The fact that 5 of the camera traps installed in the study area were either broken or stolen is an indication of a problem with poachers rather than with local people (Ünal et al., 2019). The main task falls to the Ministry of Agriculture and Forestry, VI. Regional Directorate of Nature Conservation and National Parks. In order to protect an important predator species such as the jungle cat, and increase its generation, there is a need for better implementation of the laws and regulations protecting wildlife, as well as for educational and awareness-raising activities for local people (Johannesen, 2006). Eventually, it will be imperative to take conservation priority measures for the sustainable control of wildlife and biodiversity in key habitats where endangered wild animal species are spreading.

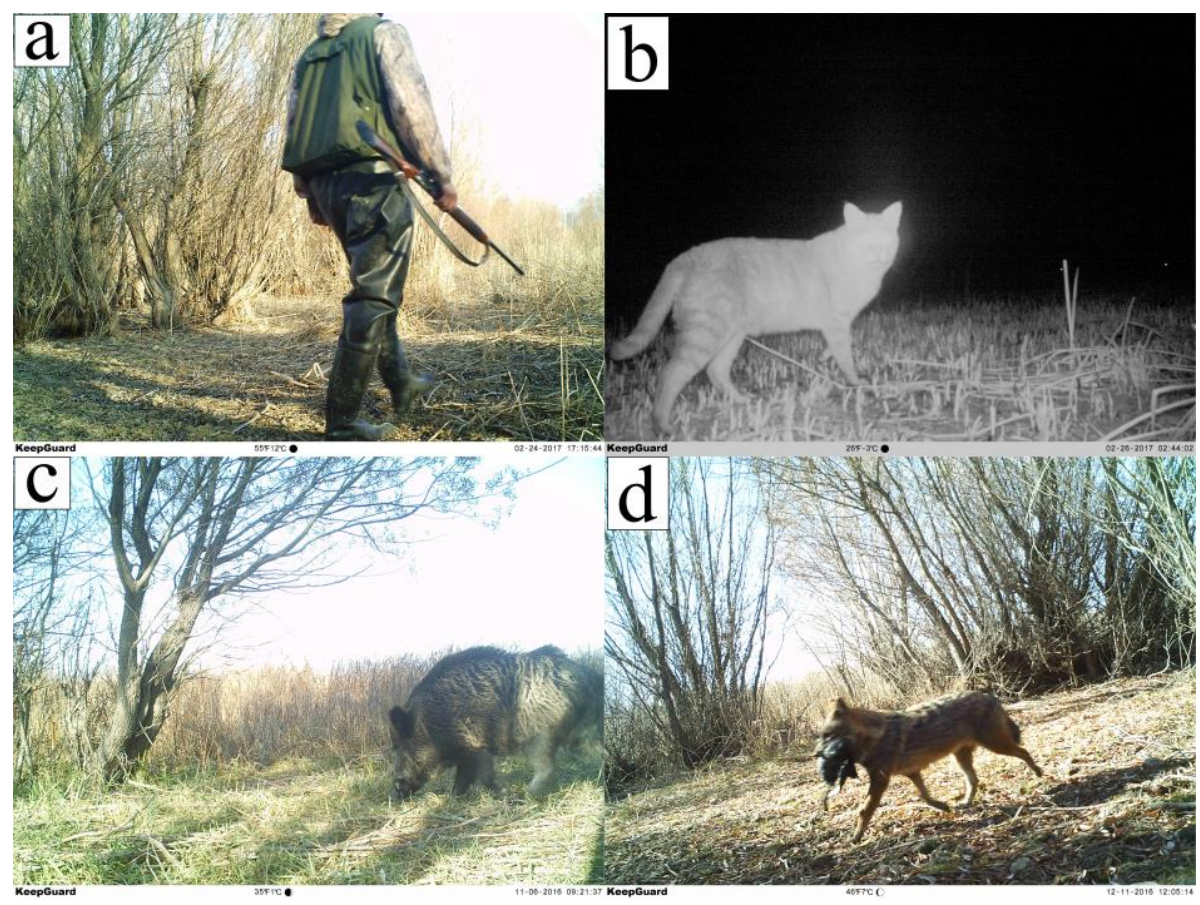

Figure 7. Photographs of a human, $b$ jungle cat, $c$ wild boar, and $d$ golden jackal captured at the same area during the study period

A nationwide monitoring program is needed to identify wildlife population dynamics and their interactions with humans and other species. This could provide an opportunity to better understand the relationship between human restrictive factors and wildlife. We believe that this study provides important insight into the interaction of rare species such as the jungle cat with humans and other wildlife species.

In order to protect wild animals, special attention should be given to environmental and wildlife awareness training, especially for wildlife habitats and rural populations. Applicable solutions should be created to reduce the pressure of mortality factors, especially poaching of wild animals. However, as the human population grows in the developing world and shifts towards wildlife habitats, it is obvious that the damage to occur will mostly affect wild animals. 


\section{Conclusion}

It is important to know that the response of a wild animal to different biotic and abiotic factors may vary between habitats. These responses can be positive or negative, but depend on the influence level of the factor. The greater the human pressure (population, poaching, recreation, etc.) in a living environment, the greater the variation of response in wild animal populations. Our research results show that the jungle cat and other wild animals have to adjust their daily behavior according to human activity in order to live and feed. In the research area, it was concluded that intense human activity in a small habitat such as $10.7 \mathrm{~km}^{2}$ creates discomfort and stress for wildlife.

The jungle cat is among the endangered species in Turkey. The jungle cat is endangered due to poaching, loss of habitats, conversion of marshes into agricultural lands, the use of pesticides to control rodent populations in agriculture areas, and the consumption of poisoned rodents. In this context new scientific research should be carried out to form the basis for the conservation of the endangered jungle cat and its habitats. Additionally, Species Protection Action Plans should be prepared by expert teams. In these plans the importance for Turkey of the national and international protection status of the jungle cat (protection status within the framework of national and international legislation and contracts), determination of jungle cat population status, habitat analysis, and determination and protection status of these areas must be updated.

Funding information. This work was supported by the Ministry of Agriculture and Forestry, VI. Regional Directorate of Nature Conservation and National Parks.

Acknowledgements. We thank the fallow deer team (Ahmet Koca, Mehmet Şirin Yelsiz, Mevlüt Zenbilci, Kürşat Bal, Hasan Uysal), we thank Ogün Çağlayan Türkay for allowing us to use his photos and we gratefully thank Ibrahim Ozdemir, and Serkan Ozdemir for analysis, comments and contribution.

\section{REFERENCES}

[1] Alcoy, J. C. O. (2013): The Schnabel method: An Ecological approach to productive vocabulary size estimation. - International Proceedings of Economics Development and Research. doi: 10.7763/IPEDR. 2013. V68. 5.

[2] Alfred, J. R. B. (2015): Estimation of population trend of lesser cats by camera trap method in Buxa Tiger Reserve, West Bengal. - Nature Environment and Wildlife Society (News) $81 \mathrm{p}$.

[3] Amaya-Castaño, G. C., Palomares, F. (2018): Effect of human influence on carnivore presence in a Mediterranean human-modified area in the Southwestern Iberian Peninsula. - Galemys 30. doi: 10.7325/Galemys.2018.A1.

[4] Ambarl1, H., Ertürk, A., Soyumert, A. (2016): Current status, distribution, and conservation of brown bear (Ursidae) and wild canids (gray wolf, golden jackal, and red fox; Canidae) in Turkey. - Turkish Journal of Zoology 40: 944-956. doi: 10.3906/zoo-1507-51.

[5] Avgan, B. (2009): Sighting of a jungle cat and the threats of its habitat in Turkey. - Cat News 50: 16.

[6] Avgan, B., Zimmermann, F., Güntert, M., Arıkan, F., Breitenmoser, U. (2014): The first density estimation of an isolated Eurasian lynx population in southwest Asia. - Wildlife Biology 20(4): 217-222.

[7] Bisi, J., Kurki, S., Svensberg, M., Liukkonen, T. (2007): Human dimensions of wolf (Canis lupus) conflicts in Finland. - European Journal of Wildlife Research 53: 304-314. doi: 10.1007/s10344-007-0092-4. 
[8] Bukhari, N., Bukhari, S., Shehzad, M. A. (2019): Capture-Recapture sampling techniques: artificial and real population data analysis. - Journal of public value and administration insights 2(3): 15-16.

[9] Can, Ö. E., Togan, I. (2004): Status and management of brown bears in Turkey. - Ursus 15(1): 48-53.

[10] Can, Ö. E., Kandemir, İ., Togan, İ. (2011): The wildcat Felis silvestris in northern Turkey: assessment of status using camera trapping. - Oryx 45(01): 112-118.

[11] Capitani, C., Chynoweth, M., Kusak, J., Coban, E., Sekercioglu, C. H. (2016): Wolf diet in an agricultural landscape of north-eastern Turkey. - Mammalia 80: 329-334. https://doi.org/10.2192/1537-6176(2004)015<0048:SAMOBB.

[12] Carbone, C., Christie, S., Conforti, K., Coulson, T., Franklin, N., Ginsberg, J. R., Laidlaw, R. (2001): The use of photographic rates to estimate densities of tigers and other cryptic mammals. - Animal Conservation forum 4(1): 75-79.

[13] Carter, N. H., Shrestha, B. K., Karki, J. B., Pradhan, N. M. B., Liu, J. (2012): Coexistence between wildlife and humans at fine spatial scales. - Proceedings of the National Academy of Sciences 109(38): 15360-15365.

[14] Carter, K. D., Seddon, J. M., Frère, C. H., Carter, J. K., Goldizen, A. W. (2013): Fissionfusion dynamics in wild giraffes may be driven by kinship, spatial overlap and individual social preferences. - Animal Behaviour 85(2): 385-394.

[15] Carter, N., Jasny, M., Gurung, B., Liu, J. (2015): Impacts of people and tigers on leopard spatiotemporal activity patterns in a global biodiversity hotspot. - Global Ecology and Conservation 3: 149-162.

[16] Chowdhury, S. U., Chowdhury, A. R., Ahmed, S., Muzaffar, S. B. (2015): Human-fishing cat conflicts and conservation needs of fishing cats in Bangladesh. - Cat News 62: 4-7.

[17] Chynoweth, M., Coban, E., Sekercioglu, C. H. (2015): Conservation of a new breeding population of Caucasian lynx (Lynx lynx dinniki) in eastern Turkey. - Turkish Journal of Zoology 39: 541-543.

[18] Dhungana, R., Savini, T., Karki, J. B., Dhakal, M., Lamichhane, B. R., Bumrungsri, S. (2017): Living with tigers Panthera tigris: patterns, correlates, and contexts of human-tiger conflict in Chitwan National Park, Nepal. - Oryx 52(01): 55-65. doi:10.1017/s0030605316001587.

[19] Di Bitetti, M. S., Di Blanco, Y. E., Pereira, J. A., Paviolo, A., Pérez, I. J. (2009): Time partitioning favors the coexistence of sympatric crab-eating foxes (Cerdocyon thous) and pampas foxes (Lycalopex gymnocercus). - Journal of Mammalogy 90: 479-490.

[20] Dickman, A. J., Macdonald, E. A., Macdonald, D. W. (2011): A review of financial instruments to pay for predator conservation and encourage human-carnivore coexistence. - Proceedings of the National Academy of Sciences 108(34): 13937-13944.

[21] Duckworth, J. W., Poole, C. M., Tizard, R. J., Walston, J. L., Timmins, R. J. (2005): The jungle cat Felis chaus in Indochina: a threatened population of a widespread and adaptable species. - Biodiversity and Conservation 14(5): 1263-1280.

[22] Durant, S. M. (1998): Competition refuges and coexistence: an example from Serengeti carnivores. - Journal of Animal Ecology 67: 370-386.

[23] Eryılmaz, A. (2017): Research on the populations of jungle cat (Felis chaus Scheberer, 1777) around the sparking in Isparta/Eğirdir Hoyran Lake. - Master Thesis, Suleyman Demirel University Graduate School of Natural and Applied Sciences Department of Enginering of Forestry, 109p.

[24] Evcin, Ö., Küçük, Ö., Akkuzu, E., Ugış, A. (2017): Habitat preferences of roe deer (Capreolus capreolus) in Kastamonu: case study of elekdağ1 wildlife development area. International Journal Of Engineerıng Sciences and Research Technology 6: 225-229.

[25] Fethi, F. Y., İleri, Ö., Avc1, K. M., Kocadere, B. (2014): Periodical Costal Line Changes of Eğirdir and Beyşehir Lakes Using Satellite Data and Topographic Maps. - Mineral Research \& Exploration Bulletin 20: 37-45. 
[26] Fitzgerald, A. (2011): Felis chaus. - Animal Diversity Web. Accessed January 09, 2020 at https://animaldiversity.org/accounts/Felis_chaus/.

[27] Forbes, K. M., Stuart, P., Mappes, T., Hoset, K. S., Henttonen, H., Huitu, O. (2014): Diet quality limits summer growth of field vole populations. - PLoS ONE 9(3): e91113. doi:10.1371/ journal.pone.0091113.

[28] Gaynor, K. M., Hojnowski, C. E., Carter, N. H., Brashares, J. S. (2018): The influence of human disturbance on wildlife nocturnality. - Science 360(6394): 1232-1235.

[29] Gerngross, P. (2014): Recent records of jungle cat in Turkey. - Cat News 61: 10-11.

[30] Giannatos, G., Albayrak, T., Erdogan, A. (2006): Status of the caracal in protected areas in southwestern Turkey. - CAT News 45: 23-24.

[31] Gray, T. N. E., Timmins, R. J., Jathana, D., Duckworth, J. W., Baral, H., Mukherjee, S. (2016): Felis chaus. - The IUCN red list of threatened specie. e.T8540A50651463.

[32] Grimm, A., Gruber, B., Henle, K. (2014): Reliability of different mark-recapture methods for population size estimation tested against reference population sizes constructed from field data. - PloS one 9(6): e98840.

[33] Gupta, S., Mondal, K., Sankar, K., Qureshi, Q. (2009): Estimation of striped hyena (Hyaena hyaena) population using camera traps in Sariska Tiger Reserve, Rajasthan, India. - Journal of the Bombay Natural History Society 106(3): 284.

[34] Hammond, P. S. (2009): Mark-recapture. - Encyclopedia of marine mammals, Academic Press. pp. 705-709.

[35] Harmsen, B. J., Foster, R. J., Silver, S. C., Ostro, L. E., Doncaster, C. P. (2011): Jaguar and puma activity patterns in relation to their main prey. - Mammalian Biology-Zeitschrift für Säugetierkunde 76(3): 320-324.

[36] Hassan, S. F., Hussin, A. G., Zubairi, Y. Z. (2009): Analysis of Malaysian wind direction data using. - Oriana 3(3): 115-119.

[37] İlemin, Y., Gürkan, B. (2010): Status and activity patterns of the caracal (Caracal caracal, Schreber, 1776), in Datca and Bozburun peninsulas, southwestern Turkey. - Zoology Middle East 50(1): 3-10. https://doi.org/ 10.1080/09397140.2010.10638405.

[38] Inskip, C., Zimmermann, A. (2009): Human-felid conflict: a review of patterns and priorities worldwide. - Oryx 43(1): 18-34.

[39] IUCN (2018): The IUCN Red List of threatened species v. 2017.3. IUCN. - Gland Accessed 20 Mar 2018. www.redlist.org.

[40] Jansen, P. A., Forrester, T. D., McShea, W. J. (2014): Protocol for camera-trap surveys of mammals at CTFS-ForestGEOsites. - Smithsonian Tropical Research Institute, Ancon.

[41] Jibasen, D. (2011): Capture-recapture Type Models for Estimating the Size of An Elusive Population. - An Unpublished PhD Thesis submitted to the University of Ilorin, Ilorin, Nigeria.

[42] Johannesen, A. B. (2006): Designing integrated conservation and development projects (ICDPs): illegal hunting, wildlife conservation, and the welfare of the local people. Environment and Development Economics 11(2): 247-267.

[43] Karanth, K. U. (1995): Estimating tiger Panthera tigris populations from camera-trap data using capture-recapture models. - Biological Conservation 71(3): 333-338. doi:10.1016/0006-3207(94)00057-w.

[44] Karanth, K. U., Nichols, J. D., Kumar, N. S., Hines, J. E. (2006): Assessing tiger population dynamics using photographic capture-recapture sampling. - Ecology 87: 2925-2937. doi:10.1890/0012-9658(2006)87 [2925:ATPDUP]2.0.CO;2.

[45] Karatepe, Y. (2004): Properties and classification of sites on Eğirdir lake watershed. İstanbul University, Institute Of Science And Technolog, Phd Thesis, 293 p. İstanbul.

[46] Kays, R. W., Slauson, K. M. (2008): Remote cameras. - In: Long, R. A., MacKay, P., Zielinski, W. J., Ray, J. C. (eds.) Noninvasive Survey Methods for Carnivores. Chapter 5, Island Press, Washington DC, USA, pp. 110-140. 
[47] Kays, R., Tilak, S., Kranstauber, B., Jansen, P. A., Carbone, C., Rowcliffe, M. J., Fountain, T., Eggert, J., He, Z. (2010): Monitoring wild animal communities with arrays of motion sensitive camera traps. - Cornell University, arXiv preprint arXiv:1009.5718.

[48] Kerley, L. L., Goodrich, J. M., Miquelle, D. G., Smirnov, E. N., Quigley, H. B., Hornocker, M. G. (2002): Effects of roads and human disturbance on amur tigers. - Conservation Biology 16(1): 97-108. doi:10.1046/j.1523-1739.2002.99290.x.

[49] Keten, A. (2016): Spatial and temporal distribution of Carnivora (Mammalia) species in Düzce Province. - Kastamonu Univ., Journal of Forestry Faculty 16(2): 566-574.

[50] Kinnaird, M. F., O'Brien, T. G. (2012): Effects of private-land use, livestock management, and human tolerance on diversity, distribution, and abundance of large African mammals. - Conservation Biology 26(6): 1026-1039.

[51] Kovach, W. L. (2011): Oriana - circular statistics for windows, ver. 4. - Pentraeth: Kovach Computing Services, Pentraeth, Wales, UK.

[52] Leuchtenberger, C., De Oliveira, Ê. S., Cariolatto, L. P., Kasper, C. B. (2018): Activity pattern of medium and large sized mammals and density estimates of Cuniculus paca (Rodentia: Cuniculidae) in the Brazilian Pampa. - Brazilian Journal of Biology 78(4): 697705. doi:10.1590/1519-6984.174403.

[53] Linkie, M., Ridout, M. S. (2011): Assessing tiger-prey interactions in Sumatran rainforests. - Journal of Zoology 284(3): 224-229. https:// doi.org/ 10.1111/j.1469-7998.2011.00801.x.

[54] Linnell, J. D. C., Swenson, J. E., Andersen, R. (2001): Predators and people: conservation of large carnivores is possible at high human densities if management policy is favourable. - Animal Conservation 4: 345-349. https://doi.org/10.1017/S1367943001001408.

[55] Madden, F. M. (2008): The growing conflict between humans and wildlife: law and policy as contributing and mitigating factors. - Journal of International Wildlife Law and Policy 11: 189-206. https://doi.org/10.1080/13880290802470281.

[56] Majumder, A., Sankar, K., Qureshi, Q., Basu, S. (2011): Food habits and temporal activity patterns of the Golden Jackal Canis aureus and the Jungle Cat Felis chaos in Pench Tiger Reserve, Madhya Pradesh. - Journal of Threatened Taxa 3(11): 2221-2225.

[57] Mengüllüoğlu, D. (2010): An inventory of medium and large mammal fauna in Pineforests of Beypazarı through camera trapping. - Graduate Thesis, Middle East Technical University, Ankara, Turkey.

[58] Mengüllüoğlu, D., Fickel, J., Hofer, H., Förster, D. W. (2019): Non-invasive faecal sampling reveals spatial organization and improves measures of genetic diversity for the conservation assessment of territorial species: Caucasian lynx as a case species. - PloS one14(5): e0216549.

[59] Mert, A., Acarer, A. (2018): Wildlife diversity in reed beds around Beyşehir lake. - Bilge International Journal of Science and Technology Research 2(1): 110-119. doi: 10.30516/bilgesci.399248.

[60] Oğurlu, İ., Gündoğdu, E., Yıldırım, C. (2010): Population status of jungle cat (Felis chaus) in Eğirdir lake, Turkey. - Journal of Environmental Biology 31: 179-183.

[61] Oğurlu, İ., Ünal, Y. (2011): A cooperation in wildlife activities by university, rural people and public authorities: wild boar census in Aksu model hunting ground. - SDU Fac For $\mathbf{J}$ 12: 7-12.

[62] Oğurlu, İ. (2015): Wildlife ecology, suleyma demirel university, faculty of forestry. - SDU printing house, publication number: 19, Isparta, $296 \mathrm{p}$.

[63] Pérez-Irineo, G., Santos-Moreno, A. (2016): Band size, activity pattern and occupancy of the coati Nasua narica (Carnivora, Procyonidae) in the Southeastern Mexican rainforest. Mammalia 80(6). doi:10.1515/mammalia-2014-0136.

[64] Pochardt, M., Allen, J. M., Hart, T., Miller, S. D., Yu, D. W., Levi, T. (2019): Environmental DNA facilitates accurate, inexpensive, and multi-year population estimates of millions of anadromous fish. - Molecular Ecology Resources 20(2): 457-467. doi:10.1111/1755-0998.13123. 
[65] Posillico, M., Serafini, P., Lovari, S. (1995): Activity patterns of the stone marten (Martes foina Erxleben, 1777), in relation to some environmental factors. - Hystrix, the Italian Journal of Mammalogy 7(1-2).

[66] Ramesh, T., Kalle, R., Sankar, K., Qureshi, Q. (2012): Spatio-temporal partitioning among large carnivores in relation to major prey species in Western Ghats. - Journal of Zoology 287(4): 269-275.

[67] Rawshan, K., Feeroz, M. M., Hasan, M. K. (2012): Human-carnivore conflicts in Bangladesh. - Tigerpaper 39(3): 17-21.

[68] Seoraj-Pillai, N., Pillay, N. (2016): A Meta-analysis of human-wildlife conflict: South African and Global Perspectives. - Sustainability 9(1): 34. doi:10.3390/su9010034.

[69] Shamoon, H., Maor, R., Saltz, D., Dayan, T. (2018): Increased mammal nocturnality in agricultural landscapes results in fragmentation due to cascading effects. - Biological conservation 226: 32-41.

[70] Sillero-Zubiri, C., Laurenson, K. (2001): Interactions between carnivores and local communities: Conflict or co-existence? - Conservation Biology Series, Cambridge University Press, pp. 282-312.

[71] Silveira, L., Jácomo, A. T. A., Diniz-Filho, J. A. F. (2003): Camera trap, line transect census and track surveys: a comparative evaluation. - Biological Conservation 114(3): 351-355. doi:10.1016/s0006-3207(03)00063-6.

[72] Silver, S. C., Ostro, L. E., Marsh, L. K., Maffei, L., Noss, A. J., Kelly, M. J., Ayala, G. (2004): The use of camera traps for estimating jaguar Panthera onca abundance and density using capture/recapture analysis. - Oryx 38(02): 148-154.

[73] Soria-Díaz, L., Monroy-Vilchis, O. (2015): Monitoring population density and activity pattern of white-tailed deer (Odocoileus virginianus) in Central Mexico, using camera trapping. - Mammalia 79(1): 43-50.

[74] Soulsbury, C. D., White, P. C. L. (2015): Human-wildlife interactions in urban ecosystems. - Wildlife Research 42(7). doi:10.1071/ wrv42n7_pr.

[75] Soyumert, A. (2010): Detection and determination of ecological characteristics of large mammal species by camera-trapping method in Northwest Anatolia forests. - Ph.D. Thesis, Hacettepe University, Ankara, Turkey.

[76] Stein, A. B., Fuller, T. K., Marker, L. L. (2008): Opportunistic use of camera traps to assess habitat-specific mammal and bird diversity in northcentral Namibia. - Biodiversity and Conservation 17(14): 3579-3587.

[77] Stolle, K., van Beest, F. M., van der Wal, E., Brook, R. K. (2015): Diurnal and nocturnal activity patterns of invasive wild boar (Sus scrofa) in Saskatchewan, Canada. - The Canadian Field-Naturalist 129(1): 76-79.

[78] Tağıl, Ş., Alevkayalı, C. (2014): Trends in Streamflow and its Relationship With Precipitation in Rivers Flowing into the Lake From the North of the Lake Eğirdir. Balikesir University, The Journal of Social Sciences Institute 17(32): 211-229.

[79] Tobler, M. W., Carrillo-Percastegui, S. E., Leite Pitman, R., Mares, R., Powell, G. (2008): Further notes on the analysis of mammal inventory data collected with camera traps. Animal Conservation 11(3): 187-189. doi: 10.1111/j.1469-1795.2008.00181.x.

[80] Treves, A., Karanth, K. U. (2003): Human-carnivore conflict and perspectives on carnivore management worldwide. - Conservation Biology 17(6): 1491-1499. doi: 10.1111/ j.15231739. 2003.00059.x.

[81] Ünal, Y., Çulhac1, H. (2018): Investigation of fallow deer (Cervus dama L.) population densities by camera trap method in Antalya Düzlerçamı Eşenadası Breeding Station. Turkish Journal of Forestry 19(1): 57-62. https://doi.org/ 10.18182/ tjf.339042.

[82] Ünal, Y., Pekin, B. K., Oğurlu, İ., Süel, H., Koca, A. (2019): Human, domestic animal, Caracal (Caracal caracal), and other wildlife species interactions in a Mediterranean forest landscape. - Eur J Wildl Res 66: 5. doi:10.1007/s10344-019-1343-x.

[83] Ünal, Y., Koca, A., Kısaarslan, Y., Yelsiz, M. Ş., Süel, H., Oğurlu, İ. (2020): Population status, daily activity pattern and habitat preference of caracal (Caracal caracal Schreber, 
1776) in Antalya Düzlerçamı Wildlife Development Area. - Turkish Journal of Forestry 20(4): 474-481.

[84] Urian, K., Gorgone, A., Read, A., Balmer, B., Wells, R. S., Berggren, P., Hammond, P. S. (2014): Recommendations for photo-identification methods used in capture-recapture models with cetaceans. - Marine Mammal Science 31(1): 298-321.

[85] URL (2017): https://tr.climate-data.org. - Last accessed: 02.11.2017.

[86] Wang, S. W., Macdonald, D. W. (2009): The use of camera traps for estimating tiger and leopard populations in the high altitude mountains of Bhutan. - Biological Conservation 142(3): 606-613.

[87] Wegge, P., Odden, M., Pokharel, C. P., Storaas, T. (2009): Predator-prey relationships and responses of ungulates and their predators to the establishment of protected areas: a case study of tigers, leopards and their prey in Bardia National Park, Nepal. - Biological Conservation 142(1): 189-202.

[88] Weingarth, K., Heibl, C., Knauer, F., Zimmermann, F., Bufka, L., Heurich, M. (2012): First estimation of eurasian lynx (Lynx lynx) abundance and density using digital cameras and capture-recapture techniques in a German National Park. - Anim. Biodivers Conserv. 35: 197-207.

[89] Woodroffe, R., Thirgood, S., Rabinowitz, A. (eds.) (2005): People and wildlife, conflict or co-existence? - (No. 9) Cambridge University Press. 